\title{
Faktor-Faktor yang Mempengaruhi Keputusan Pembelian Kopi Bubuk Banyuatis di Kota Denpasar
}

\author{
MAYSARA TAMPUBOLON, MADE ANTARA, WIDHIANTHINI \\ Program Studi Agribisnis Fakultas Pertanian Universitas Udayana \\ Jalan PB Sudirman Denpasar 80232 \\ E-mail: maysara.tampubolon@yahoo.com \\ antara_unud@yahoo.com
}

\begin{abstract}
Factors that Influence the Decision to Purchase the Banyuatis Powder Coffee in Denpasar City
\end{abstract}

The purchase decision is the act of the consumer buying a product or an item provided by a store. Consumers are influenced by information about products, prices, distribution, and promotion. In these conditions, the decision to choose a brand contributes to a modern lifestyle, so the desire to buy branded products also colors one's consumption pattern. For that, business people must know what factors are taken into consideration by consumers in making purchasing decisions. The sample studied was 85 respondents from the total unknown population with the sampling method used was accidental sampling. The primary data werecollected through interviews and questionnaires while secondary data weregathered from books and scientific documents; the method used in this study was descriptive analysis and SEM-PLS analysis. Descriptive analysis results were that Banyuatis products were based on packaging and variation; prices based on the weight of coffee sold, prices based on the type of coffee and prices based on coffee packaging; distribution is based on the type of coffee and coffee packaging, namely regular and premium, where regular distributed products are dominant in minimarkets and traditional stalls while premium products are distributed predominantly in gift shops, cafes and hotels; promotions include advertising, personal sales, sales promotions, and public relations. SEM-PLS analysis can be concluded that the product (X1), price (X2), distribution (X3), promotion (X4), and brand image (X5) had a positive and significant effect on purchasing decisions (Y) Banyuatis Powder Coffee. It is recommended that the Banyuatis Powder Coffee Company should continue to improve the quality in terms of product, price, promotion, distribution, and brand image to help improve purchasing decisions.

Keywords: Banyuatis powder coffee, consumer decisions, SEM-PLS analysis

\section{Pendahuluan}

\subsection{Latar Belakang}

Perkembangan zaman industri minuman, banyak sekali jenis produk minuman yang ditawarkan kepada konsumen, salah satu jenis produk minuman yang sudah dikenal secara umum dan menjadi gaya hidup di zaman sekarang ialah kopi. Kopi merupakan minuman hasil seduhan biji kopi yang telah disangrai dan dihaluskan menjadi bubuk. Pada tahun 2013 konsumsi kopi di Indonesia sebanyak 260.000.000 
kg kopi, sedangkan pada tahun 2014 konsumsi kopi di Indonesia meningkat menjadi $300.000 .000 \mathrm{~kg}$ kopi (Kemenperin, 2016).

Menurut Buchari (2004) keputusan pembelian merupakan tindakan konsumen membeli suatu produk atau suatu barang yang disediakan oleh sebuah toko. Para konsumen dipengaruhi oleh informasi mengenai produk, harga, distribusi dan promosi. Kondisi seperti ini, keputusan memilih merek turut berperan dalam gaya hidup modern, sehingga keinginan untuk membeli produk yang bermerek turut mewarnai pola konsumsi seseorang

Salah satu perusahaan yang menghasilkan produk kopi bubuk adalah CV. Pusaka Bali Persada yang bermerek Kopi Bubuk Banyuatis. Penjualan Kopi Bubuk Banyuatis mengalami fluktuasi. Hal tersebut karena perkembangan pesat industri minuman di Denpasar membuat tingkat persaingannya menjadi ketat. Pelaku bisnis harus tahu bagaimana membuat produk Kopi Bubuk Banyuatis bisa menjadi eksis di kalangan konsumen dan penjualannya selalu meningkat dan harus melakukan penelitian agar mengetahui faktor-faktor apa saja yang melatarbelakangi para konsumen membeli produk mereka. Berdasarkan uraian diatas maka peneliti tertarik untuk melakukan penelitian tentang "Faktor-Faktor yang Mempengaruhi Keputusan Pembelian Kopi Bubuk Banyuatis di Kota Denpasar."

\subsection{Rumusan Masalah}

Berdasarkan latar belakang, maka dapat diangkat beberapa permasalahan yang baik untuk diteliti sebagai berikut.

1. Bagaimana sistem bauran pemasaran di perusahaan Kopi Bubuk Banyuatis berdasarkan produk (product), harga (price), tempat (place), promosi (promotion)?

2. Faktor-Faktor apa yang mempengaruhi konsumen dalam melakukan keputusan pembelian produk Kopi Bubuk Banyuatis di Kota Denpasar?

\subsection{Tujuan Penelitian}

Berdasarkan rumusan masalah maka tujuan penelitian ini adalah untuk mengetahui hal-hal berikut.

1. Mengidentifikasi sistem bauran pemasaran di perusahaan Kopi Bubuk Banyuatis berdasarkan produk (product),harga (price), tempat (place), promosi (promotion).

2. Menganalisis faktor-faktor yang mempengaruhi konsumen dalam melakukan keputusan pembelian produk Kopi Bubuk Banyuatis di Kota Denpasar.

2. Metode Penelitian

\subsection{Lokasi dan Waktu Penelitian}

Penelitian ini dilakukan di kota Denpasar, dengan mengambil subjek konsumen kopi bubuk Banyuatis. Waktu penelitian ini dilakukan pada 1 Maret-15 Mei 2018.

\subsection{Data dan Metode Pengumpulan Data}

Data dalam penelitian ini berupadata kuantitatif dan data kualitatif yang berasal dari sumber primer dan sumber sekunder. Metode pengumpulan data yang digunakan adalahobservasi, wawancara, kuesioner, dan studi pustaka. 


\subsection{Populasi dan Sampel}

Populasi dalam penelitian ini adalah konsumen yang membeli dan mengkonsumsi produk Kopi Bubuk Banyuatis di Kota Denpasar yang tidak diketahui jumlahnya. Jumlah sampel responden sebanyak 85 orang yang secara kebetulan ditemui namun calon responden harus memiliki karakteristik tertentu, yaitu responden yang sedang membeli dan mengkonsumsi Kopi Bubuk Banyuatis minimal dua kali. Metode pengumpulan sampel dilakukan dengan dengan cara accidental sampling.

\subsection{Variabel Penelitian}

Variabel-variabel yang akan dianalisis dalam penelitian ini adalah produk (X1), harga (X2), distribusi (X3), promosi (X4), citra merek (X5), dan keputusan pembelian (Y).Pelaksanaan penelitian ini, peneliti memberikan skala untuk mengukur variabel-variabel yang akan diteliti melalui anggaran responden dengan menggunakan skala likert.

\subsection{Hipotesis: Produk, Harga, Distribusi, Promosi dan Citra merek berpengaruh terhadap Keputusan Pembelian}

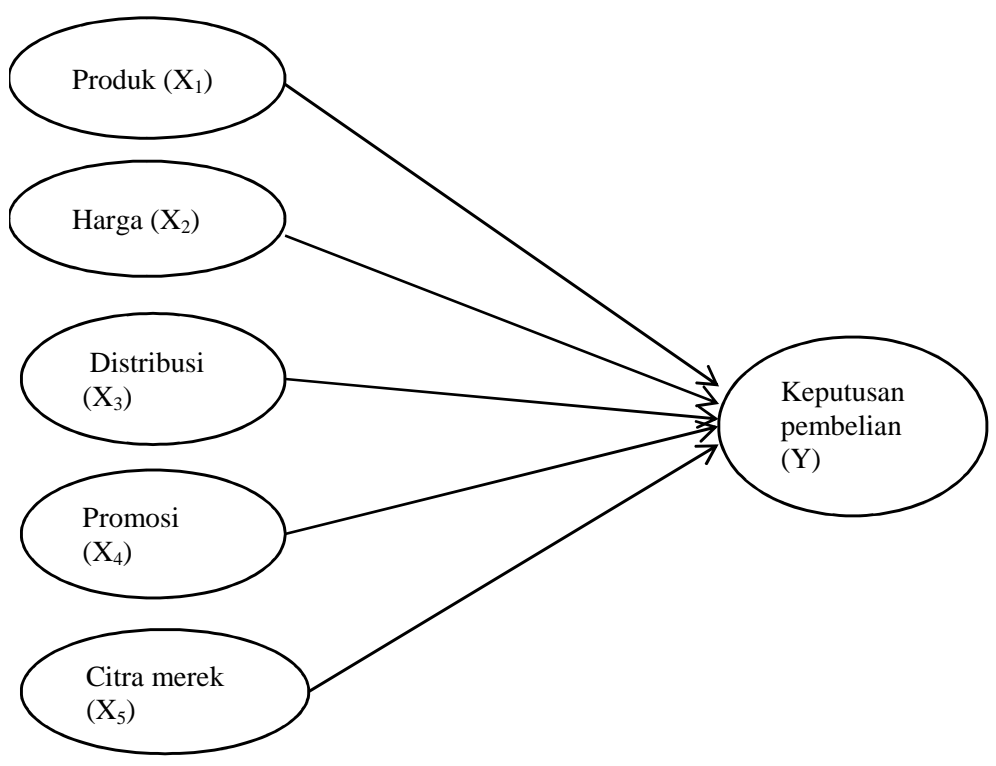

Gambar 1. Kerangka Konseptual Faktor-Faktor yang Mempengaruhi Keputusan Pembelian Kopi Bubuk Banyuatis di Kota Denpasar.

\subsection{Metode Analisis Data}

Metode analisis yang digunakan dalam penelitian ini adalah analisis kuantitatif dan deskriptif. Analisis yang digunakan untuk menjawab permasalahan pertama adalah analisis deskriptif sementara untuk menjawab permasalahan kedua menggunakan analisis SEM-PLS, alat bantu yang digunakan dalam penelitian ini berupa program Smart PLS Versi 3.0 


\section{Hasil dan Pembahasan}

\subsection{Karakteristik Responden}

Berdasarkan jenis kelamin, hasil dari kuisoner menunjukkan bahwa responden terbesar adalah perempuan sebanyak $65 \%$ (55 orang), sedangkan reponden laki-laki sebanyak 35\% (30 orang). Berdasarkan usia, menunjukan bahwa konsumen Kopi Bubuk Banyuatis lebih banyak didominasi oleh usia kerja, yakni usia 33 - 38 tahun. Berdasarkan intensitas minum kopi, menunjukan bahwa sebanyak 47 responden jarang meminum kopi untuk setiap harinya, kemudian sebanyak 38 responden sering meminum kopi untuk setiap harinya. Proporsi terbanyak responden mengkonsumsi Kopi Bubuk Banyuatis pasif sebesar 58,82\% artinya sebanyak 50 orang tidak selalu mengkonsumsi Kopi Bubuk Banyuatis, sisanya $41,17 \%$ orang aktif dalam mengkonsumsi Kopi Bubuk Banyuatis artinya sebanyak 35 orang selalu mengkonsumsi Kopi Bubuk Banyuatis.

\subsection{Bauran Pemasaran di Perusahaan Kopi Bubuk Banyuatis}

CV.Pusaka Bali Persada telah menjalankam kegiatan pemasaran yang dapat dianalisis melalui bauran pemasaran 4P yakni produk, harga, distribusi dan promosi, masing-masing bauran pemasaran memiliki kriteria sub bauran pemasaran operasinal yang berbeda-beda. Keseluruhan sub bauran yang dijalankan diantaranya produk berdasarkan kemasan dan variasi dimana perusahaan Kopi Bubuk Banyuatis memiliki produk premium dan reguler; harga berdasarkan berat kopi yang dijual, harga berdasarkan jenis kopi dan harga berdasarkan kemasan kopi; pendistribusian dilakukan berdasarkan jenis kopi dan kemasan kopi yaitu regular dan premium ,dimana produk regular didistribusikan dominan pada minimarket dan warungwarung tradisional sedangkan produk premium didistribusikan dominan pada toko oleh-oleh, kafe dan hotel; promosi meliputi periklanan, penjualan pribadi, promosi penjualan, dan hubungan masyarakat.

\subsection{Faktor-Faktor yang Mempengaruhi Konsumen dalam Melakukan Keputusan Pembelian Produk Kopi Bubuk Banyuatis di Kota Denpasar}

Pada bagian ini analisis dilakukan melalui diagram jalur yang telah dirancangmengenai analisis pengaruh dari variabel produk, harga, promosi, distribusi, dan citra merek terhadap keputusan pembelian. Langkah awal dalam permodelan PLS adalah spesifikasi model pada penelitian yang akan dilakukan. Spesifikasi model terdapat 2 macam yakni merancang outermodeldan inner model.

\subsubsection{Hasil evaluasi model pengukuran (outer model)}

Model pada Gambar 2menunjukkan bahwa terdapat 17 indikator yang memiliki loading factor lebih dari 0,7. Maka nilai diatas menunjukkan korelasi antara indikator dengan konstruknya.Penelitian tahap awal dari pengembangan skala pengukuran nilai loading factor 0,5 sampai 0,60 dianggap cukup (Ghozali, 2014) 


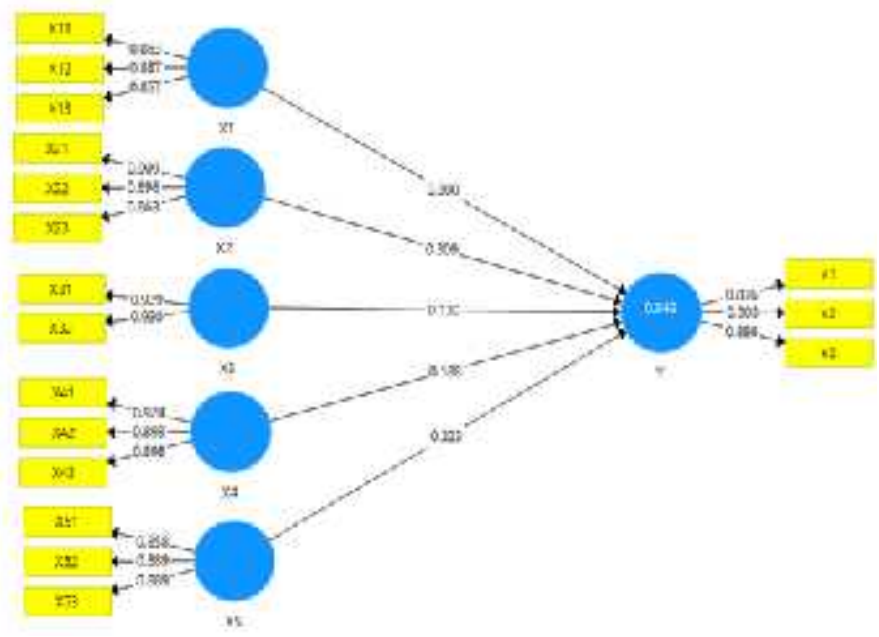

Gambar 2. Hasil Outer Model

1. Pengujian validitas model

a. Pengujian untuk convergent validity yaitu dengan melihat nilai loading factor pada model PLS. Syarat model memiliki validitas yang baik apabila masingmasing variabel laten memiliki loading factor diatas 0,7 . Berdasarkan analisis, nilai loading factor dari masing-masing variabel laten memiliki nilai diatas 0,7 dan dapat dikatakan bahwa model PLS dalam penelitian ini memenuhi syarat convergent validity yang baik.

b. Pengujian untuk discriminant validity yaitu dengan melihat nilai AVE pada model PLS. Syarat model memiliki validitas yang baik apabila masing-masing variabel laten memiliki nilai AVE diatas 0,5. Berdasarkan analisis, nilai AVE dan dari masing masing variabel laten memiliki nilai diatas 0,5 dan dapat dikatakan bahwa model PLS dalam penelitian ini memenuhi syarat discriminant validity yang baik

2. Pengujian reliabilitas model

Berdasarkan Tabel 1, hasil analisis menunjukkan semua konstruk memiliki reliabilitas yang baik, akurat dan konsisten. Terlihat memenuhi syarat dengan nilai composite reliability dan cronbach's alpha pada setiap konstruk laten memiliki nilai diatas 0,7 . Hal tersebut mengindikasikan bahwa secara komposit seluruh variabel memiliki konsistensi internal yang memadai dalam mengukur variabel laten atau variabel yang diukur sehingga dapat digunakan dalam analisis selanjutnya.

Tabel 1.

Hasil ReliabilitasOuter Model

\begin{tabular}{lcc}
\hline \multicolumn{1}{c}{ Variabel Laten } & Cronbach's Alpha & Composite Reliability \\
\hline Produk & 0.833 & 0.900 \\
\hline Harga & 0.869 & 0.920 \\
\hline Distribusi & 0.856 & 0.933 \\
\hline Promosi & 0.890 & 0.932 \\
\hline Citra merek & 0.853 & 0.911 \\
\hline $\begin{array}{l}\text { Keputusan } \\
\text { pembelian }\end{array}$ & 0.866 & 0.918 \\
\hline
\end{tabular}

Sumber: data primer yang diolah (2018) 


\subsubsection{Hasil evaluasi model structural (inner model)}

\section{Penilaian R-square}

Inner model pertama dimulai dengan melihat nilai $\mathrm{R}$-square untuk setiap variabel laten endogen. Perubahan nilai R-square dapat menjelaskan pengaruh variabel laten eksogen (produk, harga, distribusi, promosi dan citra merek) terhadap variabel laten endogen (keputusan pembelian).Berdasarkan hasil analisis menggunakan software SmartPLS versi 3.0, R-square pada variabel endogen keputusan pembelian memiliki nilai sebesar 0,849 dapat diartikan bahwa variabel laten produk, harga, distribusi, dan citra merek mampu menjelaskan variabel laten keputusan pembelian sebesar $84,9 \%$ dan sisanya $15,1 \%$ dijelaskan oleh variabel lain diluar penelitian, sehingga mengindikasikan model SEM-PLS pada penelitian ini bersifat "kuat".

2. Penilaian path coefficient hasil uji hipotesis

Hasil bootstrapping pada Tabel 2 menunjukkan semua jalur memiliki pengaruh yang signifikan $(\mathrm{T}$ statistik $>\mathrm{T}$ tabel yaitu 1,96 serta $\mathrm{P}$ value $>0,05)$ dengan signifikansi $5 \%$.

Tabel 2.

Path Coefficient

\begin{tabular}{lcccc}
\hline & $\begin{array}{c}\text { Original } \\
\text { Sample } \\
(O)\end{array}$ & $\begin{array}{c}\text { Standard } \\
\text { Deviation } \\
(\text { STDEV })\end{array}$ & $\begin{array}{c}\text { T Statistics } \\
(\mid \text { OSTDEV } \mid)\end{array}$ & P Values \\
\hline $\mathrm{X} 1$-> Y & 0,300 & 0,063 & 4,774 & 0,000 \\
\hline $\mathrm{X} 2$-> Y & 0,309 & 0,069 & 4,475 & 0,000 \\
\hline $\mathrm{X} 3$-> Y & 0,130 & 0,053 & 2,442 & 0,015 \\
\hline $\mathrm{X} 4$-> Y & 0,188 & 0,066 & 2,850 & 0,005 \\
\hline $\mathrm{X} 5$-> Y & 0,223 & 0,058 & 3,860 & 0,000 \\
\hline
\end{tabular}

Sumber: data primer yang diolah (2018)

Pengujian hipotesis tentang pengaruh produk, harga, distribusi, promosi dan citra merek terhadap keputusan pembelian Kopi Bubuk Banyuatis di Kota Denpasar, dilakukan dengan mengamati nilai Path Coefficient. Besarnya pengaruh laten eksogen terhadap laten endogen dapat dilihat dari nilai koefisien tiap jalur sehingga dapat dijelaskan pengaruhnya sebagai berikut:

1. Pengaruh produk terhadap keputusan pembelian

Berdasarkan hasil pengolahan data variabel eksogen produk berpengaruh signifikan terhadap variabel endogen keputusan pembelian konsumen dengan nilai $\mathrm{T}$ statistik sebesar 4,774 lebih besar dari nilai (t-tabel signifikansi 5\% $=1,96$ ) sehingga hipotesis H1 dapat diterima. Variabel produk berpengaruh terhadap keputusan pembelian dan memiliki nilai positif sebesar 0.300 .

2. Pengaruh harga terhadap keputusan pembelian

Berdasarkan hasil pengolahan data variabel eksogen harga berpengaruh signifikan terhadap variabel endogen keputusan pembelian konsumen dengan nilai $\mathrm{T}$ statistik sebesar 4,475 lebih besar dari nilai (t-tabel signifikansi 5\% =1,96) sehingga hipotesis H2 dapat diterima. Variabel harga berpengaruh terhadap keputusan pembelian dan memiliki nilai positif sebesar 0.309 . 
3. Pengaruh distribusi terhadap keputusan pembelian

Berdasarkan hasil pengolahan data variabel eksogen distribusi berpengaruh signifikan terhadap variabel endogen keputusan pembelian konsumen dengan nilai $\mathrm{T}$ statistik sebesar 2,442 lebih besar dari nilai (t-tabel signifikansi $5 \%=1,96)$ sehingga hipotesis H3 dapat diterima. Variabel distribusi berpengaruh terhadap keputusan pembelian dan memiliki nilai positif sebesar 0.130 .

4. Pengaruh promosi terhadap keputusan pembelian

Berdasarkan hasil pengolahan data variabel eksogen promosi berpengaruh signifikan terhadap variabel endogen keputusan pembelian konsumen dengan nilai $\mathrm{T}$ statistik sebesar 2,850 lebih besar dari nilai (t-tabel signifikansi 5\% =1,96) sehingga hipotesis H4 dapat diterima. Variabel promosi berpengaruh terhadap keputusan pembelian dan memiliki nilai positif sebesar 0.188 .

5. Pengaruh citra merek terhadap keputusan pembelian

Berdasarkan hasil pengolahan data variabel eksogen citra merek berpengaruh signifikan terhadap variabel endogen keputusan pembelian konsumen dengan nilai $\mathrm{T}$ statistik sebesar 3,860 lebih besar dari nilai (t-tabel signifikansi 5\% =1,96) sehingga hipotesis H5 dapat diterima. Variabel citra merek berpengaruh terhadap keputusan pembelian dan memiliki nilai positif sebesar 0.223 .

\subsection{Pembahasan}

Hasil penelitian dapat diketahui bahwa terdapat beberapa faktor yang berpengaruh positif dan signifkan terhadap keputusan pembelian, diantaranya ialah faktor produk, harga, distribusi, promosi, dan citra merek. Variabel produk berpengaruh positif dan signifikan terhadap keputusan pembelian Kopi Bubuk Banyuatis. Hasil penelitian ini sejalan dengan studi yang dilakukan oleh Novel (2015) yang membuktikan bahwa produk berpengaruh positif dan signifikan terhadap keputusan pembelian konsumen Kopi Luwak di Kota Semarang. Secara teoritis, konsep produk berpendapat bahwa konsumen menyukai produk yang menawarkan kualitas, kinerja, atau fitur inovatif terbaik (Kotler, 2009). Produk yang memiliki kualitas yang baik akan mempengaruhi keputusan pembelian.

Variabel harga, sampai saat ini harga yang ditawarkan sudah baik dan sesuai kualitas terbukti dengan analisis yang positif dan signifikan terhadap keputusan pembelian Kopi Bubuk Banyuatis dan hasil penelitian ini juga sejalan dengan studi yang dilakukan oleh Novel (2015) yang membuktikan bahwa harga berpengaruh positif dan signifikan terhadap keputusan pembelian Konsumen Kopi Luwak di Kota Semarang. Menurut Kotler dan Amstrong (2006) harga merupakan sejumlah uang yang dibebankan atas suatu produk atau jasa atau jumlah dari nilai yang ditukar konsumen atas manfaat manfaat karena memiliki atau menggunakan produk atau menggunakan jasa tersebut. Disimpulkan, semakin menarik harga dari produkproduk yang ditawarkan maka akan semakin meningkatkan keputusan pembelian konsumen.

Variabel distribusi berpengaruh positif dan signifikan dan hasil penelitian ini juga sejalan dengan studi yang dilakukan oleh Novel (2015) yang membuktikan bahwa distribusi berpengaruh positif dan signifikan terhadap keputusan pembelian konsumen Kopi Luwak di Kota Semarang. Secara teoritis lokasi yang strategis membuat konsumen lebih mudah dalam menjangkau dan juga keamanan yang terjamin, sehingga dengan demikian ada hubungan antara lokasi yang strategis dengan daya tarik konsumen untuk melakukan pembelian suatu produk (Akhamad, 
1996). Distribusi yang efektif akan memperlancar arus atau akses barang oleh konsumen sehingga dapat diperoleh kemudahan memperoleh barang tersebut.

Variabel promosi, promosi yang diberikan kepada konsumen berpengaruh secara positif dan signifikan dan hasil penelitian ini juga sejalan dengan studi yang dilakukan oleh Syharial (2015) yang membuktikan bahwa promosi berpengaruh positif dan signifikan terhadap keputusan pembelian pada UD.Aneka Karya Glass di Surakarta. Produsen harus lebih memperhatikan penggunaan jenis media promosi. Menurut Tjiptono (2008) menyatakan bahwa hakikatnya promosi adalah suatu bentuk komunikasi pemasaran. Adapun yang dimaksud dengan komunikasi pemasaran adalah aktivitas pemasaran yang berusaha menyebarkan informasi, mempengaruhi/membujuk, dan meningkatkan pasar sasaran atas perusahaan dan produknya agar bersedia menerima, membeli, dan loyal pada produk yang ditawarkan perusahaan yang bersangkutan. Promosi yang positif akan mempengaruhi peningkatan keputusan pembelian konsumen.

Variabel citra merek berpengaruh positif dan signifikan dan hasil penelitian ini juga sejalan dengan studi yang dilakukan oleh Devi, dkk (2015) yang membuktikan bahwa citra merek berpengaruh positif dan signifikan terhadap keputusan pembelian dan kepuasan konsumen pada layanan internet speedy di Kota Semarang. Menurut Kotler dan Keller (2009) menyatakan bahwa citra merek adalah persepsi dan keyakinan yang dilakukan oleh konsumen, seperti yang tercermin dalam asosiasi yang terjadi dalam ingatan konsumen. Citra merek yang positif akan mempengaruhi untuk peningkatan keputusan pembelian konsumen.

\section{KesimpulandanSaran}

\subsection{Kesimpulan}

1. Productberdasarkan kemasan dan variasi yaitu premium dan reguler; harga berdasarkan berat kopi yang dijual, harga berdasarkan jenis kopi dan harga berdasarkan kemasan kopi; pendistribusian dilakukan berdasarkan jenis kopi dan kemasan kopi yaitu regular dan premium ,dimana produk regular didistribusikan dominan pada minimarket dan warung-warung tradisional, sedangkan produk premium didistribusikan dominan pada toko oleh-oleh, kafe dan hotel; promosi meliputi periklanan, penjualan pribadi, promosi penjualan, dan hubungan masyarakat.

2. Hasil analisis produk, harga, distribusi, promosi, dan citra merek berpengaruh positif dan signifikan terhadap keputusan pembelian Kopi Bubuk Banyuatis.

\subsection{Saran}

Variabel produk, harga, distribusi, promosi, dan citra merek mempunyai pengaruh positif terhadap variabel keputusan pembelian, diharapkan perusahaan Kopi Bubuk Banyuatis terus meningkatkan kualitas dari segi produk yaitu meningkatkan kualitas aroma kopi, dari harga sebaiknya mempertimbangkan harga agar bersaing (kompetitif) dengan kopi lain serta harga yang ditawarkan sebaiknya sesuai kualitas produk, dan dari segi distribusi diharapkan memperluas saluran distribusi agar konsumen mudah menemukan produk, dan dari segi promosi diharapkan memperbanyak saluran media iklan agar konsumen memperoleh informasi tentang produk,serta diikuti dengan citra merek yang akan nantinya dikenal dan diingat seluruh masyarakat luas. 


\section{Ucapan Terima Kasih}

Ucapan terimakasih penulis tujukan kepada CV.Pusaka Bali Persada serta semua pihak yang telah membantu dalam pelaksanaan penelitian hingga karya ilmiah ini dapat dipublikasikan dalam bentuk e-jurnal.

\section{Daftar Pustaka}

Akhamad, J. 1996. Analisis Faktor-Faktor yang Mempengaruhi Perilaku Konsumen Warung Lesehan Di Jalan Protocol Yogyakarta. Jurnal STIE Widya Wiwaha Kajian Bisnis, Vol. 9, No. 7, hlm. 14-28

Buchari, Alma. 2004. Manajemen Pemasaran dan Pemasaran Jasa. Edisi Revisi. Bandung: Penerbit CV. Alfabeta.

Devi, Hoyyi, Mukid, 2015. Analisa Faktor-faktor Yang Mempengaruhi Keputusan Pembelian Dan Kepuasan Konsumen Pada Layanan Internet Speedy Di Kota Semarang Menggunakan Partial Least Square (PLS). https://media.neliti.com. Diakses tanggal 14 Februari 2018.

Ghozali, Imam. 2014. Metode Alternatif dengan Partial Least Square. Semarang: Badan Penerbit Universitas Diponegoro.

Kementerian perindustrian. 2016. Menperin: Gaya Hidup Dorong Industri Kopi Tumbuh.http://www.kemenperin.go.id. Diakes tanggal 26 Januari 2018

Kotler dan Amstrong. 2006. Principles of Marketing. New Jersey: Pearson International Edition.

Kotler, P. dan L. K. Keller. 2009. Manajemen Pemasaran. Edisi 12. Jilid 1. Jakarta: Penerbit PT Indeks Kelompok Gramedia.

Novel, Belgis.2015. Analisis Variabel - Variabel Yang Mempengaruhi Keputusan Pembelian Konsumen Kopi Luwak Di Kota Semarang.www.eprints.undip.ac.id. diakses tanggal 12 januari 2018.

Syahrial, 2015.Analisis Pengaruh Produk, Harga, Promosi, Dan Lokasi Terhadap Keputusan Pembelian Pada UD.Aneka Karya Glass di Surakarta. [Skripsi].Fakultas Ekonomi dan Bisnis. Universitas Muhammadiyah. Surakarta.

Tjiptono, Fandy. 2008. Strategi Pemasaran. Edisi 3. Yogyakarta: Andi. 